\title{
ESTRANHOS PASSADOS ENCONTRADOS EM UM MUSEU: A CRIANÇA E SEUS OLHARES SOBRE O TEMPO DESCONHECIDO
}

\author{
Sonia Regina Miranda*
}

\begin{abstract}
RESUMO: O objetivo desse artigo é problematizar os encontros da criança com as marcas do tempo passado no presente. Partindo de um acontecimento no qual, pela primeira vez na vida, um grupo de crianças foi um museu, discute-se, com base nas falas e estranhamentos das crianças, seus critérios de nomeação e busca de inteligibilidade desse estranho passado.
\end{abstract}

Palavras chave: Tempo histórico. Ensino de História. Aprendizagem.

\section{STRANGE PASTS FOUND IN A MUSEUM: CHILDREN AND THEIR VIEWS ON UNKNOWN TIMES}

ABSTRACT: This paper discusses children's problems when they encounter marks of past times in the present. Starting from an event in which, for the first time ever, a group of children went to a museum, it discusses their criteria to name and try to understand this strange past, based on the children's speech and uncanniness.

Key words: Historical times. History teaching. Learning.

Doutora em Educação e professora do Programa de Pós-Graduação em Educação da Universidade Federal de Juiz de Fora (UfJF). E-mail: sonia.miranda@ufjf.edu.br 
Situando um campo investigativo.

$\mathcal{H}$

á algum tempo, as pesquisas no campo da aprendizagem da história vêm se debruçando sobre o necessário entendimento acerca dos elementos que fundamentam, na criança, seu entendimento de algo que, ainda que possa assumir um lugar preponderante sob o ponto de vista da formação identitária, lhe soa, muitas vezes, como distante e pouco familiar: os elementos de um passado não vivido e não experimentado e, junto com eles, o sentido da ideia de mudança. Muitas vezes, a abstrata ideia da pré-existência de um mundo que lhe antecedeu, de que diferentes formas de ser, existir, pensar, e, sobretudo, de que os objetos que existem no mundo mudaram ao longo do tempo ou, mais do que isso, que coisas existentes hoje não existiram no passado parece, à criança, um grande absurdo. Quando se assume uma perspectiva de escuta sensível e dialógica daquilo que a criança nos traz em seus entendimentos, é possível ver que, muitas vezes, a relação que ela estabelece com o nosso conteúdo de abordagem maior - a história e o tempo - é algo, muitas vezes, ininteligível.

Uma temática em particular, no interior do campo investigativo do ensino de História, tem ocupado minhas atençóes há algum tempo: a relação entre práticas de memória e aprendizagens da História. Isso significa assumir a prerrogativa de que há múltiplos espaços que possibilitam tais aprendizagens para além da educação formal no interior da instituição escolar. Cabe, portanto, aprofundar o nível de compreensão acerca das configurações possíveis dos saberes históricos externos à escola, tendo em vista que isso pode redimensionar a natureza das práticas escolares no tocante à relação de sujeitos empíricos com o saber e, consequentemente, sua transformação em sujeitos epistêmicos (Charlot, 2001). O que pretendo apresentar neste texto deriva de uma pesquisa que buscou investigar aspectos desses entendimentos - e também de seus desentendimentos - de como a criança, ao estudar História na escola, interage com informaçôes próprias do passado, no momento em que toma contato com espaços não escolares.

Em que pese a diferença de recorte e abordagem, há um eixo compreensivo sobre o qual se estabelece o máximo de intersubjetividade: a compreensão de que o entendimento da História pelo sujeito comum, no marco da contemporaneidade, é mediado não só por aquilo que constitui o saber formalizado advindo do percurso de escolarização, 
mas também por múltiplos processos educativos escolares e não escolares. Desse modo, evoca-se continuamente a necessidade de se compreender melhor de que maneira se constituem, nos sujeitos, os processos que conferem inteligibilidade à informação histórica advinda de dentro e fora da escola. Na medida em que lidamos com distintos processos sociais e culturais que educam os sujeitos e que constituem subjetividades no tocante ao entendimento de elementos próprios da matéria histórica, aquilo que a criança estabelece como parâmetro de entendimento do passado e/ou da mudança assenta-se, muitas vezes, nas relaçốes que se estabelecem entre suas práticas de sociabilidade, os saberes escolarizados, os múltiplos lugares de memória que criam sentidos à moderna experiência do viver no espaço urbano e a indústria cultural que gravita em torno da escola.

No campo dos estudos culturais aplicados à educação, muitos têm sido os estudos relativos à interação entre infância e processos de construção de identidades. Kincheloe e Steinberg (2001) falam-nos, a esse respeito, sobre uma infância pós-moderna, cujas subjetividades são permeadas pela constituição de padróes de consumo derivados de instâncias que configuram, corporativamente, a infância na contemporaneidade. As mídias contemporâneas, associadas às corporaçôes que definem hábitos quanto a objetos de desejo, em termos de consumo, têm exercido funções importantes no sentido de funcionar como uma base de produção simbólica a partir do qual as crianças adquirem um sentido de si mesmas.

$\mathrm{Na}$ verdade, não há nada mais abstrato e distante do que o tempo e o passado. Nenhum de nós consegue apreender o passado pelos sentidos, nem tampouco experimentar a mudança temporal que se situa fora da dimensão de duração de nossa vida subjetiva. Elias (1998) nos demonstra, com bastante ênfase, que o tempo constituise como uma dimensão essencial do processo civilizador que, por um lado, é resultante de um longo processo de evolução cultural nos mecanismos de contagem e marcação temporal e, por outro lado, demanda outro complexo processo de internalização e aprendizagem por cada sujeito que, ao nascer, insere-se em uma cultura do tempo já posta. Desse modo, as próprias categorias de sucessão ou simultaneidade, por exemplo, embora essenciais sob o ponto de vista da operação intelectual que envolve seu entendimento, são derivadas de uma perspectiva temporal pautada pela continuidade histórica, o que significa 
Estranhos passados encontrados em um museu...

dizer que a mudança nesse paradigma tende a pressupor a capacidade de o estudante compreender outras possibilidades de agrupamento temporais. Apropriar-se de tais categorias significa, portanto, a um só tempo, entrar em contato com aspectos relativos a um passado histórico socialmente acumulado, mas que, ao mesmo tempo, traz em si a marca de um determinado paradigma temporal, o que náo significa dizer que não sejam aprendizagens necessárias. Portanto, pensar os processos educativos em relação à História implica, grosso modo, educar a criança para compreender e lidar com dimensões do tempo que resvalam no entendimento da mudança.

A relação da criança com o entendimento dessa mudança não se origina, contudo, no interior do espaço escolar e deriva de seu estar no mundo, suas práticas de sociabilidade que são, muitas vezes, anteriores e/ou paralelas à escola. Isso conduz-nos a uma atitude em que se torna lícito pensar que é, sobretudo, pela via das práticas de memória a que se encontra submetida no interior desse estar no mundo que a criança estabelece um primeiro sentido a respeito da variável tempo. E quais seriam as fontes de tais práticas hoje em dia? Essencialmente a família, aqui entendida como um espaço primário de construção de subjetividades, e as mídias contemporâneas, aqui entendidas como espaços prioritários de constituição e veiculação de memórias públicas na atualidade, dado seu grau de generalidade e capilaridade social.

Este artigo pretende discutir algumas dessas questôes, com ênfase naquilo que deriva das representaçôes que essa criança faz de si mesma e de como os assuntos relativos a fragmentos do passado que lhe diz respeito de modo especial - os tempos da escravidão - são processados e convertidos em explicação histórica, no momento em que a materialidade do objeto acaba por induzir a criança a uma atitude de explicação daquilo que ela vê e busca tocar.

Situando um cenário de pesquisa: crianças imaginando o passado dentro de um museu

Elisângela é uma menina negra de 11 anos, estudante do $6^{\circ}$ ano de uma escola pública na periferia de Juiz de Fora. Seu estilo falante e envolvido faz com que sempre tenha algo a dizer em relação aos assuntos que lhe são perguntados. Em casa, em meio a uma conversa bastante 
informal, sua mãe - também negra - esclarece, com muito cuidado e preocupação, que seus ascendentes "são italianos, sua avó era loira e que na família há poucos negros”. Em sua rede de ascendência, só uma avó deve, em sua avaliação, ser a culpada pelos traços fenotípicos que viriam a se manifestar em sua descendência. Dias depois, em uma visita ao Museu Mariano Procópio, onde Elisângela jamais havia estado antes, um grande volume de informaçôes, derivadas da interação com os objetos tridimensionais expostos, levaria Elisângela a emitir muitas hipóteses a respeito dos "estranhos" objetos que estavam lhe sendo apresentados naquele momento. Para todos eles, uma ideia comum a perseguia: "isso devia ser coisa de senhores de escravos, pois escravos sofriam muito e não podiam ter esses objetos”.

Sua fala, e a de muitas outras crianças que, junto com ela, viveram a experiência de, pela primeira vez, visitar um museu, serve como um passaporte para transitarmos por um território em que passado e presente se imbricam continuamente e que, por certo, merece uma atenção especial por parte de historiadores e educadores: a questão da construção de identidades na criança e seus elos com as representaçôes temporais. Trata-se de uma fala exemplar, quase replicante, localizável em um grande número de crianças de sua turma. Uma fala que nos permite situar um conjunto de questôes importantes no plano investigativo da aprendizagem em História, dentre as quais eu destacaria duas: Quais são as bases de referências a partir das quais as crianças estabelecem parâmetros explicativos a partir de um passado não tangível, porém imaginado a partir da ativação processada no interior de um museu, onde a mediação processada pelos objetos tridimensionais afeta um conjunto de sentidos? De que fontes provêm os elementos que a criança ativa no sentido de estabelecer explicações plausíveis a respeito desse passado desconhecido?

A relação da criança com o entendimento da mudança temporal não se origina no interior do espaço escolar e deriva de seu estar no mundo, suas práticas de sociabilidade que são, muitas vezes, anteriores e/ou paralelas à escola. São relações que permitem que a criança venha a ter consciência do tempo, na medida em que pressupóem a experimentação do viver que, no marco da continuidade, apresenta coisas ou situações que foram e já não são (Trepat, 2002).

Desse modo, por um lado, temos na família e nas informações e valores transmitidos por meio de elos geracionais que se pautam em 
Estranhos passados encontrados em um museu...

relações de transmissibilidade com as crianças. Isso significa dizer que, muitas vezes, o plano de informações adquirido por intermédio desses elos funciona como um filtro a partir do qual a criança processa a informação transmitida nos espaços educativos formais. Ao chegar à escola, a criança traz uma bagagem de experiências de natureza diversa que, grosso modo, se converte em memória capaz de justificar e constituir hábitos e atitudes que se repetem. Por outro lado, essa criança terá sido exposta a distintas práticas de memória no seio de seus espaços de sociabilidade anteriores e externos à escola, com especial ênfase à indústria cultural. Todas essas experiências configuram saberes que se amalgamam aos saberes formalizados pelas rotinas, conteúdos e prescrições escolares.

Estudos como os de Fernández (2006) demonstram que, ao longo da História, tem sido significativo o papel de promotores e agentes de aprendizagem fora da escola. Nesse cenário, algumas práticas, cujas reminiscências do passado situam-se, ainda, no marco temporal do presente, merecem destaque, tais como aquelas vinculadas à pregação e transmissão de valores de ordem religiosa, bem como os saberes de natureza prática transmitido pela mulher aos seus filhos e netos no interior das famílias. Isso significa dizer que tais recursos de aprendizagem saem fortalecidos pela relação que estabelecem com a oralidade e com a experiência.

Por outro lado, é possível observar, na relação com as mídias contemporâneas, a presença de outros processos educativos que formam, nos sujeitos de modo mais geral e na criança de modo particular, sentidos sobre o tempo. Tais sentidos, em certa medida, vinculam-se menos ao passado e à duração temporal e mais ao presente e à fluidez dos processos e produtos que rapidamente se transformam e desaparecem. Estes processos são mediados pela relação dos sujeitos com o mercado de consumo que, em certa medida, configura a face moderna do "ser cidadão", segundo as análises de Canclini (1999) no tocante à discussão dos processos de formação identitária. Desse modo, a conformação do sentido do "eu" precisa ser avaliada no interior da densidade peculiar que nos é acenada pelas circunstâncias contemporâneas, nas quais a inserção no mercado tem servido para redimensionar o sentido e o significado da cidadania. O acesso ao mercado e ao consumo, portanto, potencializa o sentido de fluidez temporal e de esvaziamento da vivência da duração para além do que é representado pelo instante, pelo imediato. Tal 
sentido se produz, com vitalidade cada vez mais intensa, pela via do acesso aos bens de consumo, cada vez mais fugazes e em constante transformação, o que, por sua vez, gera novas e contínuas demandas de consumo pelo "novo".

Passados imaginados dentro do museu: estranhamentos e reconhecimentos

Museus são espaços inventados na modernidade, dedicados a custodiar objetos memoráveis a partir do qual se criam discursos de memórias a serem "aprendidos". Frequentemente, quando vamos ao museu, o fazemos com o intuito de observar objetos que foram guardados e que informam sobre outro contexto temporal. Alderoqui e Camilloni (2006) destacam alguns aspectos inerentes à natureza desse espaço que nos interessa pensar neste caso particular. Trata-se de um espaço público feito para mostrar aquilo que já foi, mas não é mais privado, o que faz com que seus objetos se transformem em signos. Porém, é um espaço especial, separado da vida cotidiana, no qual a mediação do visitante se dá, com alguma aleatoriedade, pela relação física com o espaço e não com o tempo, embora sua função mais comum seja a de introduzir o espectador numa relação definida com um passado. A partir dessa relação estabelecem-se múltiplos planos de comunicação entre o visitante e o objeto gerador de sentidos, conforme nos demonstram as pesquisas de Ramos (2004). Portanto, a linguagem museográfica não é neutra e o discurso dela derivado é também um discurso produtor de memórias e de sentidos identitários, que se articulam àqueles já constituídos na criança e que são derivados dos processos educativos externos à escola.

Por que pensar tais questôes de modo apriorístico? Porque, ao entrar em contato com esses discursos construídos sobre o passado no interior da exposição, a criança não fica inerte e, em função de uma relação que passa pelos sentidos essenciais da corporeidade e pelo movimento, ela constrói sentidos para o que lhe está sendo apresentado na exposição. Há objetos que lhe serão familiares, considerando-se analogias de uso em relação àquilo que organiza seus saberes no presente. Por outro lado, os objetos apresentados numa exposição de museu não deixam de ser os elementos de cultura que "seguram" o tempo, artefatos de memória, portanto, e, nesse sentido, derivam de atitudes intencionais, por parte 
Estranhos passados encontrados em um museu...

dos grupos sociais, de lembrar ou de esquecer. Mesmo sendo estranhos, tais objetos suscitam na criança observadora atitudes de construção de sentidos pautadas naquilo que ela já sabe ou já tem de informação a respeito de algo análogo e, nesse sentido, observar tais processos de explicação conduz-nos à condição de associar de que modo esta produção de significados permite-nos estabelecer pontes em relação ao que Jedlowski (2003), ao abordar a temática da memória, designa como critérios de plausibilidade derivados das circunstâncias de pertencimento a um grupo social determinado, em uma alusão àquilo que esteve na esteira compreensiva de Halbawachs (1990) no tocante aos quadros sociais que configuram a construção de memórias e/ou de esquecimentos.

No caso particular das circunstâncias dessa pesquisa, crianças de $6^{\circ}$ ano de uma escola municipal de Juiz de Fora foram levadas ao Museu Mariano Procópio, uma importante instituição museológica nacional, cujo acervo é marcado por notável ecletismo, a despeito do predomínio, na exposição permanente, de peças relativas ao período imperial brasileiro. Como a intenção era investigar que tipo de ideias as crianças desenvolvem a partir daquilo que elas vêem na exposição de modo mais espontâneo, foi combinado que não haveria, por parte dos funcionários do Museu, nenhum tipo de interferência ou explicação. Assim, ao percorrerem livremente a exposição e ao verem os objetos segundo seus próprios interesses, as crianças iam formulando suas hipóteses acerca daquilo que lhes era apresentado.

Ao entrar em contato com uma exposição cujos objetos conduzem o olhar a um tempo não presente, a criança o faz não a partir de uma construção pautada pela cronologia e pela consideração dos marcados temporais apresentados, mas por uma notável fluidez das ideias temporais que, de um modo geral, expressam aquilo que fora demonstrado na pesquisa de Oliveira (2003 e 2006), quanto ao fato de que a criança elabora suas percepçóes primárias sobre um outro tempo a partir do que conhecem e avaliam no presente, bem como elaboram um raciocínio lógico pautado na causalidade, desprezando a cronologia na construção de seus raciocínios. Assim, quando confrontadas em relação ao parque que se situa no entorno do Museu e à construção da casa no meio das árvores, as crianças não consideram que a origem daquela mata coincide com a construção do imóvel e que, portanto, tem também uma temporalidade. Ao contrário disso, elas, grosso modo, afirmam se 
tratar de um caso em que as pessoas devem ter "desmatado só um pedacinho para colocar a casa no meio e deixaram o resto das árvores". Além disso, observa-se a presença de hipóteses muito distintas e bastante fluidas acerca da construção, que data de 1861. Todas as crianças, indistintamente, alegam tratar-se de algo "muito antigo" porque tem rachaduras e paredes descascadas, mas divergem quanto ao tempo que definiria o grau de antiguidade: algumas afirmam que a construção tem 20 anos, outras falam em 60, 100 e 200 anos. Em todos os casos, essas unidades tão díspares apresentam-se como sinônimos de "muito antigo". Somente Gabriela, de 11 anos (que também seria uma das duas únicas crianças que, ao longo da visita, assumira a postura de ler as etiquetas e legendas informadas no percurso da exposição para tentar inferir sobre o que eram os objetos que lhe eram apresentados), faria uma associação bastante lógica entre o aniversário da cidade de Juiz de Fora - tendo em vista que recentemente havia se passado o período de comemorações de 156 anos - e a construção da casa que, desse modo, teria que ser, segundo ela, posterior à origem da cidade. $\mathrm{O}$ que se destaca para o conjunto das crianças, contudo, é a fluidez com relação a essa marcação temporal. No entanto, quando invocadas acerca dos parâmetros temporais que poderiam orientar o entendimento dos objetos expostos, o conjunto das crianças entrevistadas, indistintamente, expressa opiniões que afirmam essa fluidez. Assim, a mesma Gabriela que se projetara distintivamente no momento anterior quanto à qualificação da casa, apresentaria o seguinte diálogo no percurso de visitação:

Entrevistador: Gabriela, o que é que está te chamando a atenção aqui?

Gabriela: Assim, a idade que as coisas aparentam ter, a cadeira...

Entrevistador: Você acha que essa cadeira tem quanto tempo?

Gabriela: Tem umas assim que não parece muito, mas mais de mil e quinhentos... dessas aí eu não sei.

Entrevistador: Mais ou menos quanto?

Gabriela: Ab! Uns trezentos... Nossa, olha, cadeira do estilo Napoleão, Século XVII. [Lê a etiqueta].

Entrevistador: Você acha que na época da sua bisavó existia essa cadeira assim? Gabriela: Existia. 
Entrevistador: Dessas, é?

Gabriela: Não, assim, na época da minha bisavó, não bem lá pra trás, muitos anos atrás. (...) Aquele prato também parece ser muito antigo, da antiguidade mesmo.

Entrevistador: Você acha que ele tem quanto tempo?

Gabriela: $A$, uns 50 anos.

Observa-se nesse caso uma grande variação nos critérios utilizados pela aluna ao qualificar objetos do século XIX. São "muitos anos atrás", que variam entre 50 e 1500, mesmo quando a leitura das etiquetas é capaz de fornecer um parâmetro mais controlado.

Um segundo agrupamento de ideias que merece nossa reflexão diz respeito às relaçôes que podem ser estabelecidas entre aspectos derivados da formação identitária da criança e os critérios que a mesma utiliza para qualificar esse tempo que lhe soa tão estranho. Antes de qualquer coisa, é preciso destacar que, no conjunto de ideias preliminares acerca do Museu, alguns elementos projetam-se com grande peso discursivo para aquelas crianças e, consequentemente, adquirem uma ênfase que se constitui em critério explicativo primário para o desconhecido e estranho. Um museu é visto, grosso modo, como um lugar de coisas velhas, mas, sobretudo, um lugar de coisas que pertenceram a pessoas muito importantes. No contraponto disso, não só um museu não pode comportar outros objetos de memória que não sejam também de pessoas "importantes", como também esse critério de importância passa a qualificar os objetos expostos em função de um elemento essencial às suas próprias identidades: a questão do ser afrodescendente. Vejamos, a esse respeito, duas falas emblemáticas relativas a essa explicação:

Entrevistador: O que você acha que era esse espaço (sala de jantar)?

Elisângela: Era a casa dos donos de escravos.

Entrevistador: Por que você acha que era dos donos dos escravos?

Elisângela: É que pobre não tinha dinheiro para comprar essas coisas, tinham que comer naquelas tigelas de coco, que eles não tinha dinheiro para comprar louças. Ai eu acho que isso ai era dos donos de escravos. Porque assim, os escravos não usavam isso. Ai as mucamas serviam a comida nesses pratos de luxo (...). Aquele negócio de ferro. Ai eu acho que é do século passado. Aquilo ali eu acho que é de colocar em jardim. 
Entrevistador: Isso aqui? [floreira].

Elisângela: Eu acho que era de colocar em jardim de senhores de escravos, nas fazendas. Eu acho assim, essas cadeiras eram da sala de jantar, de visita.

Elisângela: Os escravos ficavam na senzala. As mucamas ficavam abanando e faziam as coisas quando o dono delas pedia. Ai elas abanavam.

Entrevistador: Como você sabe essas coisas que você está me contando?

Elisângela: Porque a gente estuda. Nas aulas de antropologia a professora explica...

Elisângela: Aquele caldeirão parece que os escravos faziam comida. [Refere-se aqui a uma porcelana da Companhia das Índias Ocidentais].

Entrevistador: Aquilo ali você acha que servia para fazer comida?

Elisângela: Não assim, comida... mas esquentar uma água, aquele ali parece assim... de colocar no banheiro.

O cogito envolvendo a relação de apropriação dos objetos destacados traz consigo a leitura inerente à própria percepção de si em termos de pertencimento. Assim, são recorrentes entre as crianças afrodescendentes falas como as de Gabriela, ao se referir a um prato na parede: "nós negros aqui no Brasil éramos escravos e não pode ter sido dela, da minha bisavó e de alguém da minha família, bisavó da minha bisavó, tipo que trabalhava numa casa assim que tem esse prato".

As falas das crianças são significativas no sentido de apontar algo que se projeta com grande recorrência entre elas no tocante a uma dimensão da memória que lhes fora transmitida: o ressentimento da escravidão que, segundo aquilo que nos fora apontado por Ansart (2001), alia-se a um processo identitário que confere sentido a um grupo social determinado e precisa ser entendido de modo articulado ao binômio memória-esquecimento. Nesse caso particular, o fato de não saber o que é o vaso de porcelana ou o prato exposto na parede é compensado com uma explicação que se assenta sobre uma lógica definida: ter sido ou não objeto de consumo por escravos ou por senhores de escravos. Ao fazer isso, as crianças projetam para o objeto algo que lhes pertence direta ou indiretamente, pela via de uma memória socialmente construída e, nesse sentido, constituem sua própria base de entendimento frente ao passado distante materializado no objeto.

Poderíamos nos perguntar, então, de onde se originam tais bases de entendimento, na medida em que não se pode considerar esse 
Estranhos passados encontrados em um museu...

conhecimento prévio acerca da condição escrava como algo "espontâneo", mas sim como uma noção construída pela via de um dos múltiplos processos de "formação histórica" a que Rüsen (2001) se refere, ao discutir as questóes da formação da consciência. De que fontes, portanto, provêm tais conhecimentos? No caso das crianças entrevistadas, identificamos três fontes claramente tangíveis. Em primeiro lugar, da mídia televisiva que, pela via das novelas épicas, tem exercido um papel importante no sentido de projetar um tipo de memória pública, frequentemente associada ao saber histórico a ser instituído no interior do espaço escolar. A maior parte das crianças entrevistadas ou situa diretamente um plano de explicação porque "viu na novela Sinhá Moça”, ou porque há elementos tangíveis que permitem estabelecer relações plausíveis, tais como a ideia expressa de que os quartos visitados devem ter sido do "barão de Araruna [personagem da novela da Rede Globo] porque são muito parecidos". Em segundo lugar, as informações mobilizadas pelas crianças derivam da informação transmitida de modo disciplinar pela escola: "eu sei disso porque a professora me explicou na aula de História”. Contudo, essa informação escolarizada aparece, na fala das crianças, filtrada por um terceiro eixo: as referências postas no interior da família, particularmente naquilo que se remete aos próprios elementos identitários (Miranda, 2006). Pode-se aferir esse sentido a partir da fala de Elisângela:

Entrevistador: Como você sabe que nessa sala não tinha luz elétrica?

Elisângela: porque parece que eles, assim, eles usavam tocha de fogo, ai eles amarravam um pano, parece que eles colocavam na beira da janela para iluminar aqui, o lado de fora. Assim, eles usavam vela.

Entrevistador: Onde você já viu isso?

Elisângela: Assim, a minha avó me contou que, assim, ela falou que a mãe dela contava que ela colocava pedaços de pano enrolado num pau, ai eles colocavam, assim, ela conta muita história para a gente.

Nesse caso, o fato de ter ouvido uma informação sobre um tempo passado nas histórias que a avó conta e que, portanto, são mediadas por relações de afeto, a criança qualifica essa informação que, além do afeto, se associa a um sentido de testemunha ocular fidedigna e, portanto, com uma confiabilidade que supera aquilo que advém da narrativa encontrada na escola. 
Percebe-se, com essa observação mais apurada acerca de como a criança qualifica aquilo que ela desconhece em termos temporais, que ampliamos nossa condição de verificar, à luz de configuraçỗes particulares, movimentos de formação de subjetividades no entrecruzamento permanente e conflituoso entre identidade e alteridade. Tais movimentos são mutáveis e contingentes e, por esta razão, demandam um aprofundamento da prática de construção de estudos exploratórios, se é que desejamos, de fato, avançar positivamente no desafio de educar para a compreensão do tempo.

Recebido em junho de 2009 e aprovado em novembro de 2009.

\section{Referências}

ALDEROQUI, S.; CAMILLONI, A. (Org.). Museos y escuelas: socios para educar. Buenos Aires: Paidós, 2006.

ANSART, P. História e memória dos ressentimentos. In: BRESCIANI, S.; NaXara, M. (Org.). Memória e (res)sentimento. Campinas: Unicamp, 2001. p. 15-34.

CANCLINI, N. Cidadãos e consumidores. Rio de Janeiro: UFRJ, 1999.

CHARLOT, B. Da relação com o saber. Porto Alegre: ARTMED, 2001.

CUCHE, D. A noção de cultura nas ciências sociais. Bauru: EDUSC, 2002.

DIEHL, A. Cultura historiográfica: memória, identidade e representação. Bauru: EDUSC, 2002.

ELIAS, N. Sobre o tempo. Rio de Janeiro: Zahar, 1998.

FERNANDEZ, F.S. El aprendizage fuera de la escuela. Madrid: Ediciones Académicas, 2006.

HALBAWACHS, M. A memória coletiva. São Paulo: Vértice, 1990.

HUYSSEN, A. Seduzidos pela memória. Rio de Janeiro: Aeroplano, 2000.

JEDLOWSKI, P. Memórias. Temas e problemas da sociologia da memória no século Xx. Pró-posiçôes, Campinas, v. 14, n. 1(40), p. 217 234, jan./abr. 2003. 
KINCHELOE, J.; STEINBERG, S. Cultura infantil: a construção corporativa da infância. Rio de Janeiro: Civilização Brasileira, 2001

MIRANDA, S.R. et al. A história fora da escola: memórias familiares, saberes e aprendizagem em História. Juiz de Fora: UfJF, 2006. Relatório de Pesquisa (FAPEMIG).

NORA, P. Entre memóire et histoire. La problematique des lieux. In: Nora, P. Lieux de memóire. Paris: Gallimard, 1997. p. 15-42.

OLIVEIRA, S.R.F. O tempo, a criança e o ensino de História. In: RossI, V.L.S.; Zamboni, E. Quanto tempo o tempo tem. Campinas: Átomo \& Alínea, 2003. p. 145-172.

OLIVEIRA, S.R.F. Educação histórica e sala de aula: o processo de aprendizagem em alunos das séries iniciais do ensino fundamental. 2006. Tese (Doutorado em Educação) - Faculdade de Educação da Universidade Estadual de Campinas.

RAMOS, F.R.L. A danação do objeto: o museu no ensino de história. Chapecó: Argos, 2004.

RÜSEN, J. Razão histórica - Teoria da história, fundamentos da ciência histórica. Brasília, DF: UnB, 2001.

TREPAT, C. El tiempo en la didáctica de las ciencias sociales. In: TREPAT, C.; Gomes, P. El tiempo y el espacio en la didáctica de las ciencias sociales. Barcelona: Editorial Graó, 2002. p. 7-117. 